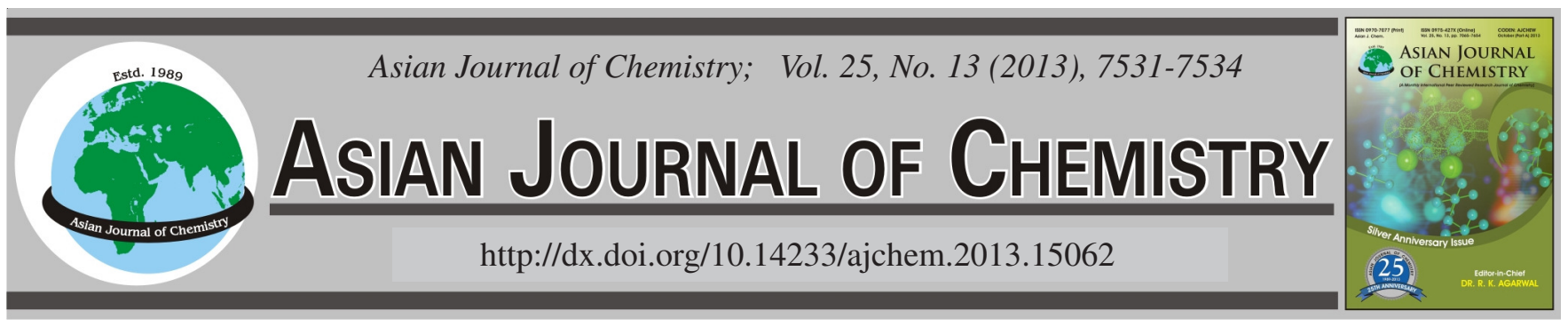

\title{
Antifungal Activity of Methanol, Acetone and Diethyl Ether Extracts of Cyanobacteria Against Plant Pathogenic Fungi
}

\author{
Kahkashan Perveen* and Hend A. Alwathnani
}

Department of Botany and Microbiology, King Saud University, P.O. Box 22452, Riyadh-11495, Kingdom of Saudi Arabia

*Corresponding author: E-mail: kperveen@ksu.edu.sa

This study was undertaken to explore the antifungal activity of methanol (ME), acetone (AE) and methanol: acetone: diethyl ether (MADE) extracts of S. platensis, T. distorta, M. aeruginosa against seven phytopathogenic fungi (F. oxysporum, Fusarium sp., F. solani, A. flavus, A. niger, A. alternata, Alternaria sp. and Cladosporium sp.). All extract gave positive results against one or more tested fungi. However, none was able to inhibit the growth of A. alternata and Alternaria sp. Moreover, MADE of all three cyanobacteria showed stimulatory effect on these two fungi. ME, AE and MADE of S. platensis were found effective against maximum number of tested fungi. All extract were able to inhibit the growth of the Cladosporium sp. but with varying degrees. AE and MADE of $S$. platensis showed strong antifungal activity (+++) against $F$. oxysporum. Whereas, MADE of $M$. aeruginosa showed strong inhibitory effect against $F$. solani and Cladosporium sp. Crude extract (MADE) of all cyanobacteria metabolites was analyzed using gas chromatography-mass spectrometry (GC-MS). Results showed that the main component in the crude extracts of S. platensis is 2-hexyl-1-nitrocyclohexane (92.1\%); T. distorta is boronic acid, ethyl-, dimethyl ester (83.9\%) and M. aeruginosa is (S)-(+)-1-cyclohexylethylamine representing $91.9 \%$.

Key Words: Antifungal activity, Gas chromatography-mass spectrometry, Crude extract of cyanobacteria, Plant pathogenic fungi.

ᄂ - - - - - - - - - - - - - - - - - - - - - - - - - - - - -

\section{INTRODUCTION}

Cyanobacteria, the blue green algae are a group of prokaryotic organisms widely distributed through out the world. These organisms are rich source of biologically active substances. Several species of cyanobacteria are known to produce intercellular and extracellular metabolites which exhibit antibacterial and antifungal ${ }^{1-5}$, antiviral ${ }^{6}$ and antialgal ${ }^{7}$ activities. One of the role which these active compound extracted from cyanobacteria can play is biological control of plant pathogenic microbes.

Plant pathogens include fungi, nematodes, bacteria and viruses which can cause damages up to various levels. Among these pathogens plant pathogenic fungi are responsible for pre and post harvest diseases including yield losses in numerous economically important crops ${ }^{8}$. A reliable strategy for the replacement of chemical fungicide has been the use of biological control. In general, extraction of bioactive compounds from cyanobacteria is performed to discover new compounds for pharmaceutical, agricultural or biological application and also for the better understanding of the interactions of these organisms within ecosystem. Extensive efforts for the identification of the bioactive compounds have been made worldwide, in order to develop safe non toxic and efficient antimicrobial agents. Several reports suggest the antimicrobial effect of metabolites/compound extracted from blue green algae ${ }^{9}$ including bacteria and fungi ${ }^{10,11}$. In the present study, we evaluated the antifungal activity of the crude extracts of cyanobacteria prepared with different solvents. Further, crude extract (MADE) of all cyanobacteria metabolites was analyzed using gas chromatography-mass spectrometry (GC-MS).

\section{EXPERIMENTAL}

Isolation and cultivation of cyanobacteria: Three species of cyanobacteria were procured from the Department of botany and microbiology, King Saud University. The test species used in the present study (Spirulina platensis, Tolypothrix distorta, Microcystis aeruginosa) were previously isolated and identified from different desert soils of Saudi Arabia. All cyanobacteria used in the present study were sub cultured in BG 11 nutrition media ${ }^{12}$ and allowed to flourish at $20-30{ }^{\circ} \mathrm{C}$ under constant light for 2-4 weeks. Cells of the active growing test cyanobacteria were harvested by filtering through Whatman No. 1 filter paper and the extracted biomass applied for extraction.

Preparation of the cyanobacterial crude extract: For the extraction of metabolites $5 \mathrm{~g}$ each of the test cyanobacteria biomass was mixed in a glass flask with $100 \mathrm{~mL}$ of methanol: 
acetone: diethyl ether $(5: 2: 1)$ and shaken for 3 days at $20{ }^{\circ} \mathrm{C}$ after that mixture was separated from biomass by filtration with Whatman No. 1 filter paper. The extract was kept in the water bath at $40^{\circ} \mathrm{C}$ under the fume hood till the extract evaporated to dryness. The obtained residue was dissolved in $2 \mathrm{~mL}$ distilled water to get the final concentration of $50 \mathrm{mg} / \mathrm{mL}$ of the crude extract. The same process was followed with the solvent acetone and methanol.

Test organisms: Pure cultures of fungal strains, $F$. oxysporum, Fusarium sp., F. solani, A. flavus, A. niger, A. alternata, Alternaria sp. and Cladosporium sp. were used in the present study. All these plant pathogenic species were isolated and identified from various diseased plants. Stock cultures of test fungi were maintained on potato dextrose agar (PDA, Scharlau Chemie, Spain) slants and were stored at $4{ }^{\circ} \mathrm{C}$.

Antifungal assay: Antifungal activity of cyanobacteria extracts were tested by agar well diffusion method. The antifungal activity was evaluated by measuring diameter of inhibition zone formed around the well. From the plates of 5 days old actively growing test fungi the spores were collected and suspended in sterile distilled water @ $1 \times 10^{6}$ spores $/ \mathrm{mL}$. Spores of test fungi were spread on the PDA with the help of sterilized cotton swab. The crude extracts $(50 \mu \mathrm{L})$ were placed in wells of $5 \mathrm{~mm}$ made on the pathogen inoculated agar plates. Wells containing only solvent served as the control. Plates were incubated for 3 days at $28 \pm 2{ }^{\circ} \mathrm{C}$ and inhibition zone of mycelial growth around the wells were measured.

GC/MS analysis of crude extracts of cyanobacteria: The composition of cyanobacterial crude extracts which showed effective antifungal activities against the test fungi were analyzed. This was done by using Perkin Elmer (Clarus 500, USA) gas chromatography coupled with (Clarus 500, USA) mass spectrometer (MS) equipped with RTx-5 column $(30 \mathrm{~nm}$ $\times 0.32 \mathrm{~nm}$ ). Oven temperature was initially held at $75^{\circ} \mathrm{C}$ for 2 min, then increased to $75-175^{\circ} \mathrm{C}$ at a rate of $50{ }^{\circ} \mathrm{C}$ per min and finally held at $175^{\circ} \mathrm{C}$ for $7 \mathrm{~min}$. Helium ( $3 \mathrm{~mL} / \mathrm{min}$ ) was used as a carrier gas. Neither internal nor external chemical standards were used in this chromatographic analysis. Interpretation of the resultant mass spectra were made using a computerized library-searching program (NIST database) and by studying the fragmentation pattern of such compound resulted from mass spectrometry analysis. Concentration of such compound was calculated by the following formula:
Compound concentration percentage $=\left[\frac{\mathrm{P}_{1}}{\mathrm{P}_{2}}\right] \times 100$

where, $\mathrm{P}_{1}$ is the peak area of the compound and $\mathrm{P}_{2}$ is whole peak areas in the fractionated extracts.

\section{RESULTS AND DISCUSSION}

The methanol (ME), acetone (AE) and methanol: acetone: diethyl ether (MADE) extracts of $S$. platensis, T. distorta, $M$. aeruginosa were assayed against seven phytopathogenic fungi (F. oxysporum, Fusarium sp., F. solani, A. flavus, A. niger, A. alternata, Alternaria sp. and Cladosporium sp.). Table-1 clearly shows that all extracts of the cyanobacteria exhibit antifungal activities against one or more tested phytopathogenic fungi. MADE of all three cyanobacteria showed the much more promising results than other extracts. However none of the extracts were able to inhibit the growth of A. alternata and Alternaria sp., infact MADE of all three cyanobacteria showed stimulatory effect on these two fungi. ME, AE and MADE of S. platensis were found effective against maximum number of tested fungi. All extract were able to inhibit the growth of the Cladosporium sp. but with varying degrees. ME and MADE of S. platensis showed strong antifungal activity (+++) against $F$. oxysporum. Whereas, MADE of $M$. aeruginosa showed strong inhibitory effect against $F$. solani and Cladosporium $\mathrm{sp}$. MADE of all three cyanobacteria gave positive results against A. niger. ME of S. platensis and M. aeruginosa and MADE of all three cyanobacteria showed weak antifungal activity (+) against $A$. flavus. Results of antifungal activity of MADE of cyanobacteria showed varying degree of inhibition of phytopathogenic fungi barring A. alternata and Alternaria sp. thus these extract were selected for GC-MS analysis. Chemical composition and concentrations of the analyzed fractions are presented in Table-2. The major peaks in the gas chromatogram were assigned with the highest percentage of the compound concentration in the total extract (REV values). The two most intensive fractions for each extract was $S$. platensis: 2-hexyl-1-nitrocyclohexane; bromoacetic acid, pentadecyl ester; $T$. distorta: boronic acid; ethyl-dimethyl ester; 7,9-di-ter-butyl-1-oxaspiro(4,5)deca-6,9-diene-2,8-dione; M. aeruginosa: (S)-(+)-1-cyclohexylethylamine; boronic acid, ethyl-dimethyl ester.

TABLE-1

ANTIFUNGAL ACTIVITY OF METHANOL, ACETONE AND METHANOL:ACETONE:DIETHYL ETHER (5: 2: 1) EXTRACTS OF S. platensis, T. distorta, M. aeruginosa

\begin{tabular}{|c|c|c|c|c|c|c|c|c|c|}
\hline & \multicolumn{3}{|c|}{ S. platensis } & \multicolumn{3}{|c|}{ T. distorta } & \multicolumn{3}{|c|}{ M. aeruginosa } \\
\hline & $\mathrm{ME}$ & $\mathrm{AE}$ & MADE & $\mathrm{ME}$ & $\mathrm{AE}$ & MADE & $\mathrm{ME}$ & $\mathrm{AE}$ & MADE \\
\hline F. oxysporum & +++ & ++ & +++ & + & - & ++ & + & - & ++ \\
\hline Fusarium sp. & + & + & ++ & + & + & ++ & + & - & ++ \\
\hline F. solani & - & - & ++ & + & - & ++ & ++ & + & +++ \\
\hline A. flavus & + & - & + & - & - & + & + & - & + \\
\hline A. niger & - & - & + & - & - & + & - & - & + \\
\hline A. alternata & - & - & - & - & - & - & - & - & - \\
\hline Alternaria sp. & - & - & - & - & - & - & - & - & - \\
\hline Cladosporium sp. & ++ & + & ++ & + & + & ++ & + & + & +++ \\
\hline
\end{tabular}

AE: Acetone extract; ME: Methanol extract; MADE: methanol: acetone: diethyl ether (5:2:1) extract. (-) no activity; (+) weak activity; (++) moderate activity; (+++) strong activity. 
TABLE-2

GC-MS ANALYSIS OF DIFFERENT COMPONENTS IN METHANOL:ACETONE:DIETHYL ETHER (5:2:1) EXTRACTS OF $S$. platensis, $T$. distorta, M. aeruginosa

\begin{tabular}{|c|c|c|}
\hline S. No. & Compound & Rev* \\
\hline \multicolumn{3}{|c|}{ Spirulina platensis } \\
\hline 1 & 1-Propanamine, N1-methyl-2-methoxy & 682 \\
\hline 2 & $\begin{array}{l}\text { 1,2-Benzendicarboxylic acid, bis(2-ethoxyethyl) } \\
\text { ester }\end{array}$ & 673 \\
\hline 3 & 1-Dodecanol, 3,7,11-trimethyl & 849 \\
\hline 4 & Hexadecen-1-ol, trans-9- & 842 \\
\hline 5 & 3-Decyn-2-ol & 838 \\
\hline 6 & $\begin{array}{l}\text { 1,6;2,3-Dianhydro-4-deoxy- } \beta \text {-D-lyxo- } \\
\text { hexopyranose }\end{array}$ & 825 \\
\hline 7 & 3-Chloropropionic acid, heptadecyl ester & 892 \\
\hline 8 & Acetic acid, chloro-, hexadecyl ester & 887 \\
\hline 9 & Bromoacetic acid, pentadecyl ester & 909 \\
\hline 10 & 10-Heneicosene $(\mathrm{C}, \mathrm{T})$ & 901 \\
\hline 11 & $\begin{array}{l}\text { 2(3H)-Furanone, } 3-(15 \text {-hexadecynylidene)dihydro- } \\
\text { 4-hydroxy-5-methyl- , }\end{array}$ & 904 \\
\hline 12 & $\begin{array}{l}\text { (3R,2E)-2-(Hex adec-15-ynyliedene)-3-hydroxy-4- } \\
\text { methylenebutanolide }\end{array}$ & 890 \\
\hline 13 & 1-Hexyl-2-nitrocyclohexane & 921 \\
\hline 14 & 1-Hexyl-1-nitrocyclohexane & 893 \\
\hline 15 & 1-Propanamine, N1-methyl-2-methoxy & 682 \\
\hline 16 & $\begin{array}{l}\text { 1,2-Benzendicarboxylic acid, bis(2-ethoxyethyl) } \\
\text { ester }\end{array}$ & 673 \\
\hline 17 & 3,7,11-Trimethyl dodecan-1-ol & 849 \\
\hline \multicolumn{3}{|c|}{ Tolypothrix distorta } \\
\hline 1 & Boronic acid, ethyl-, dimethyl ester & 839 \\
\hline 2 & 2,5-Dimethyl-3,4-hexanediol & 778 \\
\hline 3 & $\begin{array}{l}\text { 7,9-Di-ter-butyl-1-oxaspiro(4,5)deca-6,9-diene- } \\
\text { 2,8-dione }\end{array}$ & 791 \\
\hline 4 & Trichlorodecyl silane & 714 \\
\hline 5 & Tetraethylene glycol diethyl ether & 712 \\
\hline 6 & 1,1-Diethoxy ethane & 699 \\
\hline \multicolumn{3}{|c|}{ Microcystis aeruginosa } \\
\hline 1 & (S)-(+)-1-Cyclohex ylethylamine & 919 \\
\hline 2 & Octodrine & 842 \\
\hline 3 & Boronic acid, ethyl-, dimethyl ester & 849 \\
\hline 4 & 2,5-Dimethyl-3,4-hexanediol & 772 \\
\hline 5 & 3-Hydroxy butan-2-one & 831 \\
\hline 6 & (S)-Isopropyl lactate & 801 \\
\hline 7 & $\begin{array}{l}\text { 5-(1,1-Dimethylethoxy) 2-thiophene carboxylic } \\
\text { acid, }\end{array}$ & 786 \\
\hline 8 & Cyclobutanol & 790 \\
\hline 9 & 2-Dodecen-1-yl(-)succinic anhydride & 793 \\
\hline 10 & $\begin{array}{l}\text { Cyclohexanol, 4-ethyl-4-methyl-3-(1-methylethyl)- } \\
,(1 \alpha, 3 \alpha, 4-\end{array}$ & 785 \\
\hline 11 & Decane, 5,6-bis(2,2-dimethylpropy lidene)-, (E,Z)- & 782 \\
\hline 12 & $\begin{array}{l}\text { Cyclohexanol, 4-ethyl-4-methyl-3-(1-methylethyl)- } \\
,(1 \alpha, 3 \alpha, 4 \mathrm{~A}\end{array}$ & 780 \\
\hline
\end{tabular}

The current awareness of the harmful effects of chemical pesticides on the environment has encouraged the plant pathologist to evaluate cyanobacteria for use in the biological control of plant pathogenic fungi. Present study reveals that the extracts of S. platensis, T. distorta, M. aeruginosa have the potential to inhibit the growth of $F$. oxysporum, Fusarium sp., F. solani, A. flavus, A. niger and Cladosporium sp. Several studies have reported the potential of cyanobacteria as an antifungal agent ${ }^{4,13,5}$. Extracts of cyanobacteria prepared in methanol:acetone:diethyl ether mixture exhibited higher level of antifungal activity than the extract prepared in other solvents.
However, the same extracts had shown the stimulatory effect on A. alternata and Alternaria sp. Rania and Taha ${ }^{14}$, tested the antimicrobial activity of ethanol, acetone, diethyl ether and methanol extracts of Anabaena oryzae, T. ceytonica, S. platensis, Chlorella pyrenoidosa and Scenedesmus quadricauda against various organisms that incite diseases of humans and plants pathogenic fungi (A. niger, A. flavus, Penicillium herquei, $F$. moniliforme, Helminthosporium sp., A. brassicae, Saccharomyces cerevisiae, Candida albicans). In the study, they found that, S. platensis and A. oryzae had the highest antibacterial and antifungal activity towards the tested bacteria and fungi. Recently, Kamble et al. ${ }^{5}$ reported that the cold water extract of Hydrodictyon reticulatum, Schizomeris leibleinii, Spirogyra plena and Plectonema gracillimum had the total inhibitory effect on A. alternata, A. flavus and F. roseum, whereas extract of Nitella batrachosperma, S. platensis and Phormidium corium had stimulatory property for the same plant pathogenic fungi. These results are in line with our findings.

ME and MADE of $S$. platensis showed strong antifungal activity (+++) against $F$. oxysporum. It has been reported that culture filtrates or cell extracts from cyanobacteria applied to seeds protect them from damping-off fungi such as Fusarium sp., Pythium sp. and Rhizoctonia solani $i^{4}$. Our study revealed that MADE of M. aeruginosa had strong inhibitory effect against $F$. solani and Cladosporium sp. Earlier, the diethyl ether extract of M. aeruginosa gave the largest inhibition zones on the agar plates of the Saccharomyces cerevisiae and Candida albicans $^{15}$.

In the present study the crude extracts (MADE) of all cyanobacteria was analyzed using gas chromatography-mass spectrometry (GC-MS). Results showed that the main component in the crude extracts of $S$. platensis is nitrocyclohexane2-hexyl-1 (92.1\%); T. distorta is boronic acid, ethyl-, dimethyl ester (83.9 \%) and M. aeruginosa is (S)-(+)-1cyclohexylethylamine representing $91.9 \%$. The antimicrobial activity of microalgae has been attributed to compounds belonging to several chemical classes-including indoles, terpenes, acetogenins, phenols, fatty acids and volatile halogenated hydrocarbons ${ }^{16,17}$; for instance, the antimicrobial activity of supercritical extracts obtained from the microalga Chaetoceros muelleri were related to its lipid composition ${ }^{18}$. However, the antimicrobial activity detected in several pressurized extracts from Dunaliella salina may be explained not only by several fatty acids, but also by such compounds as $\alpha$ - and $\beta$-ionone, $\beta$-cyclocitral, neophytadiene and phytol $^{19}$. Pressurized liquid ethanol extracts of $H$. pluvialis were tested by Santoyo $e$ al $^{20}$ against $C$. albicans and A. niger; all extracts were active against the former, but not against $A$. niger. The main compounds responsible for such antifungal activity were claimed to be butanoic acid and methyl lactate.

The findings of present study showed that the cyanobacteria S. platensis, T. distorta, M. aeruginosa have the potential to be exploited as biocontrol agents of plant pathogenic fungi. Further, efforts should be made to identify the compounds directly responsible for those antifungal features and to develop suitable formulations of culture filtrates which can be used as a protectant/fungicides against plant pathogenic fungi. 


\section{ACKNOWLEDGEMENTS}

The authors extended their appreciation to the Deanship of Scientific Research at King Saud University for funding the work through the research group project No. RGP-VPP086.

\section{REFERENCES}

1. Y. Ghasemi, Y.M. Tabatabaei, S. Shokravi, N. Soltani and G. Zarrini, J. Sci. Islamic Rep. Iran, 14, 203 (2003).

2. T. Demiriz, C. Cokmus and K. Pabuccu, Asian J. Chem., 23, 1384 (2011).

3. N. Soltani, R.A. Khavari-Nejad, Y.M. Tabatabaei, S.H. Shokravi and E. Fernandez-Valiente, Pharm. Biol., 43, 455 (2005).

4. M.M. Kulik, Eur. J. Plant Pathol., 101, 585 (1995).

5. S.M. Kamble, A.U. Rokde and A.M. Chavan, Int. Multidis. Res. J., 2 , 23 (2012).

6. R.E. Moore, C. Cheuk, X.G. Yang and G.M.L. Patterson, J. Org. Chem., 52, 1036 (1989).

7. D.M. John, B.A. Whitton and A.J. Brook, Cambridge University Press, Cambridge, pp. 117-122 (2003).

8. J. Fletcher, C. Bender, B. Budowle, W.T. Cobb, S.E. Gold, C.A. Ishimaru, D. Luster, U. Melcher, R. Murch, H. Scherm, R.C Seem, J.L. Sherwood, B.W. Sobral and S.A. Tolin, Microbiol. Mol. Biol. Rev., 70, 450 (2006).
9. H.M. Amaro, A.C. Guedes and F.X. Malcata, In ed.: A. Méndez Vilas, Formatex, pp. 1272-1280 (2011).

10. R.B. Volk and F.H. Furkert, Microbiol. Res., 161, 180 (2006).

11. G. Sethubathi and V.A. Prabu, Curr. Res. J. Biol. Sci., 2, 24 (2010).

12. R. Rippka, J. Deruelles, J. Waterbury, M. Herdman and R. Stanier, J. Gen. Microbiol., 111, 1 (1979).

13. A. Cosveanu, O. Axine and B. Iacomil, Scientific Papers, UASVM Bucharest, Series A, Vol. LIII, pp. $442-447$ (2010).

14. M.A.A. Rania and H.M. Taha, Global J. Biotechnol. Biochem., 3, 22 (2008).

15. V. Madhumathi, P. Deepa, S. Jeyachandran, C. Manoharan and S. Vijayakumar, Int. J. Microbiol. Res., 2, 213 (2011).

16. A.M.S. Mayer and M. Hamann, Comp. Biochem. Physiol. C, 140, 265 (2005).

17. K.H.M. Cardozo, T. Guaratini, M.P. Barros, V.R. Falcão, A.P Tonon, N.P. Lopes, S. Campos, M.A. Torres, A.O. Souza, P. Colepicolo and E. Pinto, Toxicol. Pharmacol., 146, 60 (2007).

18. J.A. Mendiola, C.F. Torres, P.J. Martín-Alvarez, S. Santoyo, A. Toré, B.O. Arredondo, F.J. Señoráns, A. Cifuentes and E. Ibáñez, Eur. Food Res. Technol., 224, 505 (2007).

19. M. Herrero, E. Ibañez, A. Cifuentes, G. Reglero and S. Santoyo, J. Food Prot., 69, 2471 (2006).

20. S. Santoyo, I. Rodríguez-Meizoso, A. Cifuentes, L. Jaime, R.G. GarcíaBlairsy, F.J. Eñorans and E. Ibáñez, LWT-Food Sci. Technol., 42, 1213 (2009). 